\title{
Determinants of favourable opinions about euthanasia in a sample of French physicians

\author{
Lionel Dany ${ }^{1,2}$, Karine Baumstarck ${ }^{3,6^{*}}$, Eric Dudoit ${ }^{1,2}$, Florence Duffaud ${ }^{1}$, Pascal Auquier ${ }^{3,6}$ and Sébastien Salas ${ }^{1,4,5}$
}

\begin{abstract}
Background: The question whether euthanasia should be legalised has led to substantial public debate in France. The objective of this study in a sample of French physicians was to establish the potential determinants of a favourable opinion about euthanasia in general and when faced with a specific situation as embodied in the Humbert affair.

Methods: The study was a cross-sectional survey investigating two different samples of medical doctors: (1) those specialised in palliative care and affiliated to the French Society for Patient Accompaniment and Palliative Care; (2) medical interns (medical doctors in training course) in a French medical university (Marseille). A questionnaire was sent (email) to each voluntary participant including sociodemographics, professional status, mention of believing in God, and opinion about euthanasia (the question was designed to assess the general opinion about euthanasia and the opinion about a specific case, the Vincent Humbert' case (a man who was rendered quadriplegic, blind, and mute after an accident and has requested euthanasia).

Results: A total of 413 physicians participated in the research (participation rate: $48.5 \%$ ). Less than half of the population were favourable to euthanasia in general and almost two-thirds of the population were favourable to Vincent Humbert's request for euthanasia. Based on the multivariate analysis, individuals believing in God and being a medical intern were significant independent factors linked to having a favourable opinion about euthanasia in general and about the Vincent Humbert's request.
\end{abstract}

Discussion: There is still no study in France on the development of opinion about euthanasia and its impact. The issue goes beyond the strictly professional sphere and involves broader socio-political stakes. These stakes do not necessarily take into account medical practices and experiences or the desires of end-of-life patients. The professional upheaval that the future French legal framework will doubtlessly trigger will require further research.

Conclusion: The professional upheaval that the future French legal framework will doubtlessly trigger will require further research.

Keywords: Euthanasia, Opinions, Physicians

\section{Background}

The issue of the legalization of euthanasia has kindled substantial public debate in several developed countries $[1,2]$ and particularly in France [3]. In France, a law (also called 'the Leonetti law', April 22nd 2005) concerning the rights of patients at the end of life allows the limitation or discontinuation of treatment and sedation

\footnotetext{
* Correspondence: karine.baumstarck@univ-amu.fr

${ }^{3}$ Unité d'Aide Méthodologique à la Recherche Clinique et Epidémiologique, AP-HM, Marseille, France

${ }^{6}$ EA3279, Self-perceived Health Assessment Research Unit, Aix Marseille Université, 27 bd Jean Moulin, Marseille cedex 05 F-13385, France Full list of author information is available at the end of the article
}

for a symptom that has remained refractory until death, thereby differentiating such situations from euthanasia [4]. While euthanasia remains prohibited, much of the French population is in favour of the legalization of euthanasia. A recent poll (October 2014) conducted by a large French polling agency (Institut français d'opinion publique, IFOP) [5] found $96 \%$ of French people to be in favour of doctors "putting an end, without suffering, to the lives of persons with an unbearable and incurable illness, if they so wish".

To take these opinions into consideration and with a view to modifying the present law in France, several official 
reports and opinion surveys about the decriminalization of euthanasia or physician-assisted suicide have been requested by the French government. As highlighted by a previous report of the French National Ethics Advisory Committee (CCNE), most of those calling for the decriminalization of euthanasia or physician-assisted suicide do so in response to specific intolerable situations they have seen afflicting their relatives at the end of life [6]. In practice, it seems that approximately $9 \%$ of terminally ill patients have expressed the wish to die but only few patients repeat their request for euthanasia, and that such requests are most often related to uncontrolled symptoms [7].

In France as in other countries [8-10], public debate and viewpoints concerning euthanasia are constantly fuelled by individual or specific situations (e.g., people with severe disability, in a vegetative state or in an endof-life situation). Owing to their mediatization, such situations have become a key component in the debates and controversies associated with euthanasia. Indeed, our perceptions and judgments about various aspects of our environment are influenced by the process of exemplification that the media create [11]. In the last few years, a specific case in France has led to much comment and debate in society concerning the request for euthanasia. Vincent Humbert (1981-2003) was a young man who was rendered quadriplegic, blind and mute after a serious road accident. In 2002 and with the assistance of an educator, he wrote a letter to the French President (Jacques Chirac) to ask him to be given the "right to die". Because the request was not granted, his mother assisted by a doctor "helped" Vincent to die in September 2003. The Humbert affair led the French Government to set up a parliamentary mission to examine accompaniment at the end of life and the Leonetti law.

Performing euthanasia is considered an act that only the medical profession can carry out so it is important to investigate to what extent the medical profession accepts it. This context and the stakes for health care professionals led us to investigate the opinion of different types of physicians about this issue.

International professional acceptance of euthanasia varies widely [12-18]. We can observe differences in opinions on euthanasia and assisted suicide between physicians (less favourable), other healthcare professionals and general public (more liberal). Among health professionals, being religious is generally associated with a negative attitude towards euthanasia [12, 19, 20]. Moreover, more the physicians are involved in palliative care procedures (professional practices, training), less they are favourable to the legalization of euthanasia [13, 17, 18]. Additionally, the opinions on euthanasia and physician-assisted suicide are influenced by the suffering situations on which people must express their opinions [14, 17]. The legal context also influences opinions expressed toward euthanasia. For example, physicians in Belgium and The Netherlands (countries where euthanasia is legal) are more favourable to euthanasia [12].

The objectives of this study in a sample of French physicians were to establish the potential determinants of a favourable opinion about euthanasia: i) in general and ii) when faced with a specific situation as embodied in the Humbert affair.

\section{Methods \\ Design}

The study was a cross-sectional survey investigating two different samples of medical doctors: (1) those specialised in palliative care and affiliated to the French Society for Patient Accompaniment and Palliative Care; (2) medical interns (a 'medical intern' corresponds to a medical doctor in training course; after the sixth year of medical studies, the medical intern practices in the hospital, provides medical treatment or performs surgery under the supervision of a senior doctor) of a French medical university (Marseille, South of France) who are in their 7th and 8th years of the training course. Mailing lists were provided by the French Society for Patient Accompaniment and Palliative Care and the university. The exclusion criterion was refusal to participate. A questionnaire including the following data was sent via e-mail to all eligible individuals: i) sociodemographics (sex, age, marital status, children); ii) information relative to professional status (supplementary specialization, palliative care experience); iii) one item relative to believing in God ('Do you believe in God?' yes/no) and one item concerning the history of caring for someone in a palliative care situation; iv) opinion about euthanasia using a 6-point scale encoded from 1 strongly disagree to 6 strongly agree; the question was designed to assess the general opinion about euthanasia and to know what the subjects thought about the case of Vincent Humbert. French euthanasia law defines euthanasia as the intentional ending of a life by the administration of medication by a physician at the explicit request of a patient. This is the definition that has been used in this work. Physicianassisted suicide is the practice of providing a competent patient with a prescription for medication for the patient to use with the primary intention of ending his or her own life. French law considers euthanasia as illegal and subject of a criminal penalty. French law does not use the term "physician-assisted suicide".

\section{Ethics}

The study conformed to the principles of the Declaration of Helsinki and French Good Clinical Practices. This present study is defined as an non-interventional research as mentioned in articles L.1121-41 and R.1121-2 of the 
French Public Health code: it does not involve products mentioned in article L.5311-1 of the French Code of Public Health and does not imply any changes in the medical care received by the patients. According to the French law (Article L1121-1, Law n²011-2012 29 december 2011-art. 5), ethical approval is not needed. All subjects participated voluntary. All participants were informed about the objectives and the design of the research and participated after giving their consent. Anonymity and confidentiality were maintained during the survey.

\section{Statistical analysis}

The data are expressed as frequencies and percentages for categorical variables. Euthanasia opinions (general opinion and opinion about Vincent Humbert) initially collected from the 6-point scale were re-coded in a binary variable [17]: scores from 1 to 3 represented an unfavourable opinion and scores from 4 to 6 were considered favourable. Comparisons between the favourable and unfavourable groups were performed using the chi-square or Fisher's exact tests for frequencies. Multivariate analysis using logistic regression models were performed using a forward stepwise approach to determine variables potentially linked to a favourable opinion. Variables relevant to the models were selected on their clinical interest and/or a threshold $p$-value $\leq 0.2$ in univariate analysis (gender was systematically entered into the model). The final models expressed the odds ratios and $95 \%$ confidence intervals. All the tests were two-sided. Statistical significance was defined as $p<0.05$. Statistical analyses were performed using the SPSS version 19.0 software package (SPSS Inc., Chicago, IL, USA).

\section{Results}

\section{Population}

In total, 413 physicians participated in the research. The participation rate was 48.1 and $48.6 \%$ for medical doctors specialised in palliative care and training course medical doctors respectively. The socio-demographic and professional characteristics of the sample are summarized in Table 1. The mean age was 34.3 years (standard deviation SD: 11.1) and the sex ratio was 0.73 . Half of them declared they believe in God and the same proportion had taken care of someone nearing the end of life. Nearly six out of 10 physicians were medical interns and more than two-thirds were specialised in general practice.

\section{Opinion about euthanasia in general}

Less than half of the population were favourable to euthanasia in general. Univariate analysis showed that younger physicians, single physicians, those without any children, those who had not taken care of someone nearing the end of life and those specialised in general practice were more favourable to euthanasia. Medical interns
Table 1 Characteristics of the sample

\begin{tabular}{|c|c|c|}
\hline & Number & Percent \\
\hline \multicolumn{3}{|l|}{ Gender } \\
\hline Female & 239 & 57.9 \\
\hline Male & 174 & 42.1 \\
\hline \multicolumn{3}{|l|}{ Age } \\
\hline$\leq 27$ years & 215 & 52.1 \\
\hline$>27$ years & 198 & 47.9 \\
\hline \multicolumn{3}{|l|}{ Marital status } \\
\hline Couple & 281 & 68.0 \\
\hline Single & 132 & 32.0 \\
\hline \multicolumn{3}{|l|}{ Child } \\
\hline Yes & 163 & 39.5 \\
\hline No & 250 & 60.5 \\
\hline \multicolumn{3}{|l|}{ Believes in God } \\
\hline Yes & 210 & 50.8 \\
\hline No & 203 & 49.2 \\
\hline \multicolumn{3}{|c|}{ Has taken care of someone nearing the end of life } \\
\hline Yes & 203 & 49.2 \\
\hline No & 210 & 50.8 \\
\hline \multicolumn{3}{|l|}{ Professional status } \\
\hline Palliative care specialists & 170 & 41.2 \\
\hline Medical interns & 243 & 58.8 \\
\hline \multicolumn{3}{|l|}{ Specialisation } \\
\hline General practice & 283 & 68.5 \\
\hline Others $^{a}$ & 130 & 31.5 \\
\hline \multicolumn{3}{|l|}{ Opinion about euthanasia } \\
\hline Unfavourable & 232 & 56.2 \\
\hline Favourable & 181 & 43.8 \\
\hline \multicolumn{3}{|c|}{$\begin{array}{l}\text { Opinion about the demand of euthanasia of Vincent } \\
\text { Humbert }\end{array}$} \\
\hline Unfavourable & 167 & 40.4 \\
\hline Favourable & 246 & 59.6 \\
\hline
\end{tabular}

aOthers: oncology, surgery, anaesthesia, psychiatry, pneumology, public health, gynaecology

were significantly more favourable to euthanasia than palliative care specialists. Based on the multivariate analysis, individuals believing in God and being a medical intern were significant independent factors linked to having a favourable opinion about euthanasia in general. The results were detailed in Table 2.

\section{Opinion about Vincent Humbert's request for euthanasia}

Almost two-thirds of the population were favourable to Vincent Humbert's request for euthanasia. Univariate analysis showed that younger physicians, single physicians, those without children, those who had not taken care of someone nearing the end of life, medical interns and those 
Table 2 Opinion about euthanasia in general

\begin{tabular}{|c|c|c|c|c|c|c|c|}
\hline & & \multicolumn{2}{|l|}{ Opinion } & \multirow{3}{*}{$p^{\mathrm{a}}$} & \multicolumn{2}{|c|}{ Multiple regression ${ }^{\mathrm{b}}$} & \multirow{3}{*}{$p$} \\
\hline & & Unfavourable (1) & Favourable (2) & & OR & IC (95\%) & \\
\hline & & n (\%) & n (\%) & & (1) ver & sus (2) & \\
\hline \multirow[t]{2}{*}{ Gender } & Female $(n=239)$ & $140(58.6)$ & $99(41.4)$ & 0.146 & 1 & {$[0.74-2.25]$} & 0.353 \\
\hline & Male $(n=174)$ & $92(52.9)$ & $82(47.1)$ & & 1.29 & & \\
\hline \multirow[t]{2}{*}{ Age } & $>27$ years $(n=198)$ & $172(86.9)$ & $26(13.1)$ & $<0.001$ & 1 & {$[0.42-2.55]$} & 0.924 \\
\hline & $\leq 27$ years $(n=215)$ & $60(27.9)$ & $155(72.1)$ & & 1.04 & & \\
\hline \multirow[t]{2}{*}{ Marital status } & Couple $(n=281)$ & $179(63.7)$ & $102(36.3)$ & $<0.001$ & 1 & {$[0.47-1.48]$} & 0.539 \\
\hline & Single $(n=132)$ & $53(40.2)$ & 79 (59.8) & & 0.83 & & \\
\hline \multirow[t]{2}{*}{ Child } & Yes $(n=163)$ & 151 (92.6) & $12(7.4)$ & $<0.001$ & 1 & {$[0.47-4.73]$} & 0.493 \\
\hline & No $(n=250)$ & $81(32.4)$ & $169(67.6)$ & & 1.49 & & \\
\hline \multirow[t]{2}{*}{ Believes in God } & No $(n=203)$ & 119 (58.6) & $84(41.4)$ & 0.188 & 1 & [1.08-3.26] & 0.024 \\
\hline & Yes $(n=210)$ & $113(53.8)$ & $97(46.2)$ & & 1.88 & & \\
\hline \multirow[t]{2}{*}{ Has taken care of someone nearing the end of life } & Yes $(n=203)$ & $133(66.0)$ & $68(34.0)$ & $<0.001$ & 1 & {$[0.72-2.15]$} & 0.429 \\
\hline & No $(n=210)$ & $98(46.7)$ & $112(53.3)$ & & 1.24 & & \\
\hline \multirow[t]{2}{*}{ Professional status } & $\begin{array}{l}\text { Pall care specialists } \\
(n=170)\end{array}$ & $164(96.5)$ & $6(3.5)$ & $<0.001$ & 1 & {$[13.18-248.22]$} & $<0.001$ \\
\hline & $\begin{array}{l}\text { Medical interns } \\
(n=243)\end{array}$ & $68(28.0)$ & $175(72.0)$ & & 57.20 & & \\
\hline \multirow[t]{2}{*}{ Specialisation } & Others $(n=130)^{c}$ & $84(64.6)$ & $46(35.4)$ & 0.012 & 1 & {$[0.43-1.54]$} & 0.548 \\
\hline & $\begin{array}{l}\text { General practice } \\
(n=283)\end{array}$ & $148(52.3)$ & $135(47.7)$ & & 0.82 & & \\
\hline
\end{tabular}

${ }^{a} p$-Value for Pearson's $x^{2}$

${ }^{\mathrm{b}}$ Hosmer-Lemeshow test: $p=0.316$

'Others: oncology, surgery, anaesthesia, psychiatry, pneumology, public health, gynaecology

specialised in general practice were more favourable to Vincent Humbert's request. Multivariate analysis showed that independent factors associated with a favourable opinion about Vincent Humbert's request were believing in God and being a medical intern. The results were detailed in Table 3.

\section{Discussion}

While $96 \%$ of French people-have-been found to be in favour of euthanasia, fewer than $50 \%$ of physicians were favorable to it. This underlines the fact that this is an important medical and social problem in France, as it also is worldwide. Euthanasia is defined by the law in only three countries in Europe [16], we decided to study the potential determinants of being favourable to euthanasia in a sample of French physicians. One of the most important findings in this study is the difference between the two populations of physicians concerning their opinion about euthanasia. Most of the medical students were in favour of it whereas palliative care specialists were largely opposed. In this sense, medical interns seem to have opinion close to that of the French population [5]. In addition, while physicians were unfavourable to euthanasia, their opinions were not as categorical when they were faced with the specific case of Vincent
Humbert. Physicians, and specifically palliative care specialists, presumably took a "principled stance" linked to their professional identity when they express their opinion about euthanasia in general. When they were faced with a specific case, their stance was nuanced because they were confronted with a different level of personal involvement. Their opinions may have varied depending on the clinical situation. They were even more in favour of euthanasia since such patients are symptomatic and have a major handicap while most patients in palliative care are cancer patients who may be symptomatic but remain valid.

The medical interns are younger and less (or not) experienced concerning end-of-life and palliative care. Research has shown that the physicians most heavily involved in palliative care (training, management of patients at the end of life) are the least in favour of the legalisation of euthanasia, are more aware of the aims of palliative care, and are in favour of the professionalization of this medical speciality $[13,17,18]$. Furthermore, the WHO definition of palliative care, like the definition given by the French Society of Accompaniment and Palliative Care (Société Française d'Accompagnement et de soins Palliatifs, SFAP), specifies that the aim of palliative care is neither to hasten nor postpone death' [21, 22]. In other words, the opinions expressed toward euthanasia by our 
Table 3 Opinion about Vincent Humbert's request for euthanasia

\begin{tabular}{|c|c|c|c|c|c|c|c|}
\hline & & \multicolumn{2}{|l|}{ Opinion } & \multirow{3}{*}{$p^{a}$} & \multicolumn{2}{|c|}{ Multiple regression $^{\text {b }}$} & \multirow{3}{*}{$p$} \\
\hline & & Unfavourable (1) & Favourable (2) & & $\mathrm{OR}$ & IC (95\%) & \\
\hline & & n (\%) & n (\%) & & (1) ve & sus (2) & \\
\hline \multirow[t]{2}{*}{ Gender } & Female $(n=237)$ & 94 (39.3) & $145(60.7)$ & 0.332 & 1 & {$[0.37-1.20]$} & 0.184 \\
\hline & Male $(n=174)$ & $73(42.0)$ & $101(58.0)$ & & 0.67 & & \\
\hline \multirow[t]{2}{*}{ Age } & $>27$ years $(n=196)$ & $141(71.2)$ & $57(28.8)$ & $<0.001$ & 1 & {$[0.10-2.14]$} & 0.330 \\
\hline & $\leq 27$ years $(n=215)$ & $26(12.1)$ & $189(87.9)$ & & 0.47 & & \\
\hline \multirow[t]{2}{*}{ Marital status } & Couple $(n=281)$ & $138(49.1)$ & $143(50.9)$ & $<0.001$ & 1 & [0.52-1.99] & 0.956 \\
\hline & Single $(n=132)$ & $29(22.0)$ & $103(78.0)$ & & 1.01 & & \\
\hline \multirow[t]{2}{*}{ Child } & Yes $(n=163)$ & $127(77.9)$ & $36(22.1)$ & $<0.001$ & 1 & {$[0.49-3.70]$} & 0.563 \\
\hline & No $(n=250)$ & $40(16.0)$ & $210(84.0)$ & & 1.34 & & \\
\hline \multirow[t]{2}{*}{ Believes in God } & No $(n=203)$ & $88(43.3)$ & $115(56.7)$ & 0.139 & 1 & {$[1.27-4.21]$} & 0.006 \\
\hline & Yes $(n=210)$ & 79 (37.6) & $131(62.4)$ & & 2.31 & & \\
\hline \multirow[t]{2}{*}{ Has taken care of someone nearing the end of life } & Yes $(n=203$ & $96(47.8)$ & $105(52.2)$ & 0.002 & 1 & {$[0.45-1.48]$} & 0.512 \\
\hline & No $(n=210)$ & $70(33.3)$ & $140(66.7)$ & & 0.82 & & \\
\hline \multirow[t]{2}{*}{ Professional status } & Pall care spec $(n=170)$ & $139(81.8)$ & $31(18.2)$ & $<0.001$ & 1 & {$[12.63-409.22]$} & $<0.001$ \\
\hline & $\begin{array}{l}\text { Medical interns } \\
(n=243)\end{array}$ & $28(11.5)$ & $215(88.5)$ & & 71.91 & & \\
\hline \multirow[t]{2}{*}{ Specialisation } & Others $(n=130)^{c}$ & $63(48.5)$ & $67(51.5)$ & 0.016 & 1 & {$[0.42-1.46]$} & 0.447 \\
\hline & $\begin{array}{l}\text { General practice } \\
(n=283)\end{array}$ & $104(36.7)$ & $179(63.3)$ & & 0.78 & & \\
\hline
\end{tabular}

${ }^{a} p$-Value for Pearson's $x^{2}$

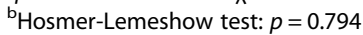

'Others: oncology, surgery, anaesthesia, psychiatry, pneumology, public health, gynaecology

sample highlight the professional and personal stakes involved. For palliative care professionals, opposition to euthanasia is particularly important in order to maintain their professional legitimacy [18]. As pointed out by others, the relationship between palliative care and euthanasia comprises semantic and strategic issues related to the professionalization of palliative care. For example, attitudes toward the professionalization of palliative care and proximity with its providers influence beliefs about which medical practices should be labelled as euthanasia [17].

Another explanation that may explain the distance that palliative care specialists take regarding the issue, is that only few terminally ill patients express a wish to die or repeatedly request euthanasia [6]. In fact, the question of euthanasia is not central to their professional practice and the relatively rareness of such requests from patients may distance them from it. Finally, the difference in opinion between palliative care specialists and medical interns could be analysed in terms of a generational difference since the on-going social debate in France in recent years may have served to change the way future physicians regard this issue in general.

Promoting palliative care and advocating the legalization of voluntary euthanasia and assisted suicide (VE/AS) are generally viewed as opposite causes [23]. Both positions represent traditionally opposed currents of thought but also reflect concern for many common values (i.e. reducing human suffering; not reducing patients to a purely vegetative state; empowering patients at the end of life) [23]. Promoting the development of palliative care is often put forward as an alternative in debates on mooted changes to laws concerning the end of life, with the risk of reinforcing opposition between palliative care organizations and advocates of euthanasia.

Differences in opinion toward euthanasia may not be related only to professional identity or professional stakes. In our study, believing in God was associated with a more favourable opinion about it. This finding differs from others that demonstrate a link between religiosity and opposition toward euthanasia. Indeed, the independent effect of religiosity has been extensively discussed in previous studies [19, 20]. Beyond religious affiliation, strong religiosity has an impact on opinion about legalization of euthanasia $[19,20]$. For example, supporting such legalization was less frequent among physicians attending religious services at least once a month [13]. In other study we showed that stronger religious belief was associated with more positive support for euthanasia [24]. However, the measures used to assess religiosity in these studies were not the same. Some authors built a religiosity index including different items, as "believing in God?" for example [25]. Other studies 
used more specific questions as the "religious affiliation" [15], the "belief in the church's teachings" [16], or the "attendance to religious services" [17]. In our study, the association between "believing in God" and a more favourable opinion toward euthanasia can be explained by the specificity of the used question. But considering that "belief in God" constitutes a quasi-philosophical thinking, does not imply, for people, a strong religiosity or the adherence to strict dogma. In our study, we did not ask the respondents for their religious affiliation because surveys in France are seldom allowed to ask such questions. In addition, we did not ask a more general question about spirituality because the term 'spirituality' in French has several meanings. Furthermore we did not assess the level of religiosity but a more general belief concerning God. People who declare they believe in God are able express nuanced positions about key issues such as the "sanctity of life", patient autonomy and other ethical issues.

The implementation of palliative care is closely linked to considerations within society concerning conditions at the end of life and euthanasia. This issue is frequently addressed in the specialist literature on palliative care [26]. While most of the French population is in favour of euthanasia, it is not authorised under French law. Our results are important because the issue is very topical at present within French society. The French National Assembly recently proposed legislation (17 March 2015) concerning the end of life and adopted at the first reading a bill that establishes a right to "deep continuous sedation" for end-of-life patients and makes binding any advance care that the patient may plan. Future modifications to legislation in France concerning the end of life will likely accentuate the debate concerning the specificities of palliative care practices and their ethical and identity issues. Palliative care specialists could be brought to question their opposition to euthanasia and the extent to which they can remain neutral on the issue [27].

We arbitrary decided to consider the euthanasia opinion as a binary variable, with the recoding from the 6-point scale, leading to a loss of information and a reduction of the statistical power to detect a relation between the variable and patient outcome. However, our choice remains on three main arguments. This approach: i) is already used in similar work $[17,28]$, ii) leads to easier interpretation and presentation of results, and iii) permits comparisons in the French context.

\section{Conclusion}

There is still no study in France on the development of opinion about euthanasia and its impact. The debate related to euthanasia probably exceeds the socio-political stakes and also concerns the healthcare professional sphere. In addition, these stakes do not necessarily take into account medical practices and experiences or the desires of end-of-life patients. The professional upheaval that the future French legal framework will doubtlessly trigger will require further research.

\section{Competing interests}

The authors report that there are no conflicts of interest.

\section{Authors' contributions}

Conception and design: LD, SS, FD. Study coordination: LD, SS. Acquisition of data: LD, SS, ED. Analysis of data: LD, KB, PA. Drafting and writing of manuscript: LD, KB, SS. All authors read and approved the final manuscript.

\section{Author details}

${ }^{1}$ APHM, Timone, Service d'Oncologie Médicale, 13385 Marseille, France. ${ }^{2}$ LPS EA849, Aix-Marseille Université, 13621 Aix-en-Provence, France. ${ }^{3}$ Unité d'Aide Méthodologique à la Recherche Clinique et Epidémiologique, AP-HM, Marseille, France. ${ }^{4} \mathrm{CRO} 2$, Aix Marseille Université, 13284 Marseille, France. 5INSERM U911, 13005 Marseille, France. ${ }^{6}$ EA3279, Self-perceived Health Assessment Research Unit, Aix Marseille Université, 27 bd Jean Moulin, Marseille cedex 05 F-13385, France.

Received: 10 July 2015 Accepted: 27 October 2015

Published online: 05 November 2015

\section{References}

1. Dees MK, Vernooij-Dassen MJ, Dekkers WJ, Elwyn G, Vissers KC, van Weel C. Perspectives of decision-making in requests for euthanasia: A qualitative research among patients relatives and treating physicians in The Netherlands. Palliat Med. 2013;27:27-37.

2. Macleod RD, Wilson DM, Malpas P. Assisted or hastened death: the healthcare practitioner's di-lemma. Glob J Health Sci. 2012;4:87-98.

3. Ferrand $E$, Rondeau E, Lemaire F, Fischler M. Requests for euthanasia and palliative care in France. Lancet. 2011;377:467-8.

4. Loi du 22 avril $2005, n^{\circ} 2005-370$ relative aux droits des malades et à la fin de vie. Journal Officiel de la République Française. http://www.legifrance.gouv.fr/ affichTexte.do?cidTexte=JORFTEXT000000446240\&categorieLien=id.

5. Sondage IFOP Euthanasie. http://www.ifop.com/media/poll/2818-1-study_file.pdf. Octobre 2014.

6. Comité Consultatif National d'Ethique: Avis 121: fin de vie, autonomie de la personne, volonté de mourir. http://www.ccne-ethique.fr/sites/default/files/ publications/avis_121_0.pdf.

7. Guirimand F, Dubois E, Laporte L, Richard JF, Leboul D. Death wishes and explicit requests for euthanasia in a palliative care hospital: an analysis of patients files. BMC Palliat Care. 2014;13:53.

8. Dany L, Dudoit E, Lienhart AS, Favre R. La presse française face aux soins palliatifs et à l'euthanasie. Rev Inter Soins Palliat. 2006;21:55-9.

9. Somerville MA. Euthanasia in the media: journalist' values, media ethics and "public square" messages. Hum Health Care Int. 1997;13:17-20.

10. Striano P, Bifulco F, Servillo G. The saga of Eluana Englaro: another tragedy feeding the media. Intensive Care Med. 2009;35:1129-31.

11. Zillmann D, Brosius H-B. Exemplification in communication. Mahwah: Lawrence Erlbaum; 2000.

12. Gielen J, Van Den Branden S, Broeckaert B. Attitudes of European physicians toward euthanasia and physician-assisted suicide: a review of the recent literature. J Palliat Care. 2008;24(3):173-84

13. Grassi L, Magnani K, Ercolani M. Attitudes toward euthanasia and physicianassisted suicide among Italian primary care physicians. J Pain Symptom Manage. 1999;17:188-96.

14. Kouwenhoven PS, Raijmakers NJ, van Delden JJ, Rietjens JA, Schermer MH, van Thiel G, et al. Opinions of health care professionals and the public after eight years of euthanasia legislation in the Netherlands: A mixed methods approach. Palliat Med. 2013;27:273-80.

15. Lavoie M, Godin G, Vézina-Im LA, Blondeau D, Martineau I, Roy L. Psychosocial determinants of physicians' intention to practice euthanasia in palliative care. BMC Med Ethics. 2015;16:6.

16. Parpa E, Mystakidou K, Tsilika E, Sakkas P, Patiraki E, Pistevou-Gombaki K, et al. Attitudes of health care professionals, relatives of advanced cancer patients and public towards euthanasia and physician assisted suicide. Health Pol. 2010;97:160-5. 
17. Peretti-Watel P, Bendiane MK, Moatti JP. Attitudes toward palliative care, conceptions of euthanasia and opinions about its legalization among French physicians. Soc Sci Med. 2005;60:1781-93.

18. Portenoy RK, Coyle N, Kash KM, Brescia F, Scanlon C, O'hare D, et al. Determinants of the willingness to endorse assisted suicide. A survey of physicians, nurses, and social workers. Psychosomatics. 1997;3:277-87.

19. Caddell DP, Newton RE. Euthanasia: american attitudes toward the physician's role. Soc Sci Med. 1995;40:1671-81.

20. McDonald WL. Situational factors and attitudes toward voluntary euthanasia. Soc Sci Med. 1998;46:73-81.

21. WHO. WHO definition of palliative care. http://www.who.int/cancer/palliative/ definition/en. Accessed 8th April 2015.

22. SFAP. SFAP definition of palliative care. http://www.sfap.org/rubrique/lessoins-palliatifs-en-france. Accessed 8th April 2015

23. Hurst SA, Mauron A. The ethics of palliative care and euthanasia: exploring common values. Palliative Med. 2006;20:107-12.

24. Hains CAM, Hulbert-Williams NJ. Attitudes toward euthanasia and physicianassisted suicide: a study of the multivariate effects of healthcare training, patient characteristics, religion and locus of control. J Med Ethics. 2013;39:713-6

25. Verbakel E, Jaspers E. A comparative study on permissiveness toward euthanasia religiosity, slippery slope, autonomy, and death with dignity. Public Opin Q. 2010;74:109-39.

26. Hermsen MA, Ten Have H. Euthanasia in palliative care journals. J Pain Symptom Manage. 2002;23:517-25.

27. Johnstone M-J. Organization position statements and the stance of « studied neutrality » on euthanasia in palliative care. J Pain Symptom Manage. 2012:44:896-907.

28. Peretti-Watel P, Bendiane MK, Pegliasco H, Lapiana JM, Favre R, Galinier A, et al. Doctors' opinions on euthanasia, end of life care, and doctor-patient communication: telephone survey in France. BMJ. 2003;327:595-6.

\section{Submit your next manuscript to BioMed Central and take full advantage of:}

- Convenient online submission

- Thorough peer review

- No space constraints or color figure charges

- Immediate publication on acceptance

- Inclusion in PubMed, CAS, Scopus and Google Scholar

- Research which is freely available for redistribution 